Напольских Дмитрий Леонидович

кандидат экономических наук, доцент кафедры управления и права

Поволжского государственного

технологического университета

Фурин Александр Геннадьевич

кандидат экономических наук, доцент кафедры экономической теории

Поволжского государственного

технологического университета

\section{СИСТЕМАТИЗАЦИЯ \\ ПЕРСПЕКТИВНЫХ МОДЕЛЕЙ ПРОСТРАНСТВЕННОГО РАЗВИТИЯ РОССИЙСКОЙ ФЕДЕРАЦИИ [1]}

\section{Аннотация:}

Объектом настоящего исследования являются теоретико-методологические основы формирования моделей пространственного развития российских регионов. Цель работы заключается в систематизации подобных перспективных моделей, расширяющих методологический потенциал оптимального размещения кластерных инициатив 6 экономическом пространстве страны. В ходе анализа определены ключевые тенденции и возможности реализации стратегии пространственного развития Российской Федерации. Выделены «полюсы» данного процесса, обобщены главные фракторы неравномерности структуры расселения и расположения производительных сил на территории государства. Детально представлены три базовые модели пространственного развития: полииентрическая, равномерно-иерархическая и кластерно-сетевая. Автор выдвигает положение о рассмотрении формирования в российских регионах промышленных кластеров в качестве фактора трансформации экономического пространства. Изучены значимые социально-экономические эффекты реализации кластерно-сетевой модели пространственного развития России.

Ключевые слова:

система расселения, агломерации, кластеры, пространственное развитие, экономическое пространство.

\section{Napolskikh Dmitry Leonidovich}

PhD in Economics Associate Professor, Management and Law Department, Volga State University of Technology

Furin Aleksandr Gennadyevich

$\mathrm{PhD}$ in Economics, Associate Professor, Economic Theory Department, Volga State University of Technology

\section{THE SYSTEMATIZATION OF PROMISING SPATIAL DEVELOPMENT MODELS FOR THE RUSSIAN FEDERATION [1]}

Summary:

The research focuses on the theoretical and methodological bases for creating spatial development models in Russian regions. The purpose of the study is to systematize these promising models to provide more methodological opportunities for cluster initiatives in the economic space of the country. The analysis identifies the key trends in and the feasibility of the spatial development strategy of the Russian Federation. The poles of this process are defined; the main factors in the unequal settlement and distribution of productive forces in Russian regions are summarized. The authors elaborate on three basic models of spatial development (polycentric, uniform hierarchical, networking and cluster ones). They assume that industrial clusters can be developed in Russian regions as a transforming factor in the economic space. The paper examines the significant social and economic effects of the networking and cluster model of spatial development in Russia.

Keywords:

settlement system, agglomeration, clusters, spatial development, economic space.

Введение. На сегодняшний день научный поиск дополнительных точек роста эфффективности процессов инновационного развития российской экономики находится на региональном уровне. Федеральным законом № 172-Ф3 от 28.06.2014 г. «О стратегическом планировании в Российской Федерации» закреплен порядок разработки Стратегии пространственного развития [2]. В рамках подготовки данного принципиально нового для страны стратегического документа сочетаются подходы инновационного и территориального планирования. В проекте Стратегии закреплены следующие положения пространственного развития России: перспективная экономическая специализация отдельных территорий субъектов РФ в межрегиональном разделении труда; прогноз комплексного развития транспортной, инновационной и социальной инфраструктуры при перспективной экономической специализации отдельных территорий российских регионов; перечень планируемых территорий опережающего социально-экономического развития на основе размещения национальных технологических платформ.

При этом для современного пространственного развития регионов России характерны тенденции ослабления внутренних экономических связей и снижения интегрирующей роли террито- 
риально-производственных комплексов, сформированных в рамках предыдущей модели экономического районирования территории страны. Сохранение данных процессов оказывает негативное влияние на результативность стратегий социально-экономического развития субъектов РФ и актуализирует научную задачу совершенствования теоретико-методологических подходов к пространственному развитию регионов на основе формирования кластеров в целях повышения конкурентоспособности национальной экономики.

Факторы и тенденции пространственного развития России. Современную систему пространственного развития Российской Федерации образуют системы расселения [3], разделенные на шесть иерархических уровней (таблица 1). В число центров шестого (общероссийского) уровня расселения входят следующие города: Москва, Санкт-Петербург, Севастополь, Ростов-на-Дону, Ставрополь, Нижний Новгород, Екатеринбург, Новосибирск, Хабаровск, Воронеж, Краснодар, Волгоград, Казань, Уфа, Самара, Пермь, Челябинск, Омск, Красноярск, Иркутск, Владивосток [4]. Изменения структуры агломераций на территории России и системы расселения в целом за первые полтора десятилетия XXI столетия характеризуются процессами поляризации и усилением пространственной неравномерности расселения и размещения производительных сил.

Таблица 1 - Иерархические уровни системы расселения в РФ [5]

\begin{tabular}{|l|l|l|}
\hline \multicolumn{1}{|c|}{$\begin{array}{l}\text { Иерархический } \\
\text { уровень }\end{array}$} & $\begin{array}{c}\text { Административное деление } \\
\text { обуниципальные } \\
\text { образования и т. д.) }\end{array}$ & \multicolumn{1}{c|}{$\begin{array}{c}\text { Географическое деление } \\
\text { (населенные пункты) }\end{array}$} \\
\hline $\begin{array}{l}\text { Первый } \\
\text { (поселенческий) }\end{array}$ & $\begin{array}{l}\text { Городские округи, городские и } \\
\text { сельские поселения }\end{array}$ & $\begin{array}{l}\text { Деревни, села, станицы, поселки городского } \\
\text { типа, города и т. д. }\end{array}$ \\
\hline $\begin{array}{l}\text { Второй } \\
\text { (районный) }\end{array}$ & Муниципальные районы & $\begin{array}{l}\text { Агломерации городских и сельских населен- } \\
\text { ных пунктов в границах одного района }\end{array}$ \\
\hline $\begin{array}{l}\text { Третий } \\
\text { (межрайонный) }\end{array}$ & Часть территории субъекта РФ & $\begin{array}{l}\text { Агломерации городских и сельских населен- } \\
\text { ных пунктов на территории нескольких райо- } \\
\text { нов }\end{array}$ \\
\hline $\begin{array}{l}\text { Четвертый } \\
\text { (региональный) }\end{array}$ & Субъект РФ & $\begin{array}{l}\text { Территории преимущественного расселения и } \\
\text { агломерации в границах субъекта РФ }\end{array}$ \\
\hline $\begin{array}{l}\text { Пятый } \\
\text { (межрегиональный) }\end{array}$ & $\begin{array}{l}\text { Территории преимущественного расселения и } \\
\text { агломерации в нескольких субъектах РФ }\end{array}$ \\
\hline $\begin{array}{l}\text { Шестой } \\
\text { (национальный) }\end{array}$ & $\begin{array}{l}\text { Российская Федерация (сосед- } \\
\text { ние фредеральные округи) }\end{array}$ & Крупнейшие агломерации мегаполисов \\
\hline
\end{tabular}

В проекте Стратегии пространственного развития РФ на период до 2030 г. в качестве первого «полюса», фрормирующего пространственную неравномерность развития страны, рассматривается Московская агломерация (Московский столичный регион), расположенная на территории двух субъектов РФ: города федерального значения Москвы и Московской области. За анализируемый период 2000-2016 гг. население этой агломерации увеличилось более чем на 3,5 млн чел. и на сегодняшний день превышает 12,00 \% общей численности граждан государства. Следует подчеркнуть, что Московская агломерация по площади составляет всего 0,27 \% от общей территории Российской Федерации [6].

В качестве противоположного «полюса», формирующего пространственную неравномерность развития России, рассматриваются «внеагломерационные территории», площадь которых превышает 96 \% всего государства. Динамика расселения здесь характеризуется следующими тенденциями: численность населения за анализируемый период 2000-2016 гг. уменьшилась на 8 млн чел. (снижение с 48 до 43 \% от общей численности населения РФ), плотность населения также сократилась с 4,0 до 3,5 чел./км². На сегодняшний день количество жителей второго пространственного «полюса» составляет приблизительно 63 млн чел. [7].

Пространственная структура агломераций в Российской Федерации на 2014 г. представлена на рисунке 1. Сегодня отмечается сохранение данной структуры расселения и размещения производительных сил.

На основании анализа пространственного расположения агломераций в Российской Федерации можно сделать вывод о высокой степени неравномерности структуры расселения и расположения производительных сил на территории страны, что проявляется в следующем:

- прослеживается четкое разделение государства на две неравные части: западную европейскую (23 \% территории, 5 федеральных округов) и восточную азиатскую (77 \%, 3 округа);

- в европейской части РФ находятся 87 агломераций, в которых живут свыше 65 млн чел., что составляет около 45 \% совокупного населения России;

- в азиатской части размещаются 37 агломераций, в них проживает более 20 млн чел., что составляет около 14 \% населения [8].

Расположенные на территории России агломерации систематизированы в таблице 2 в зависимости от численности населения. 


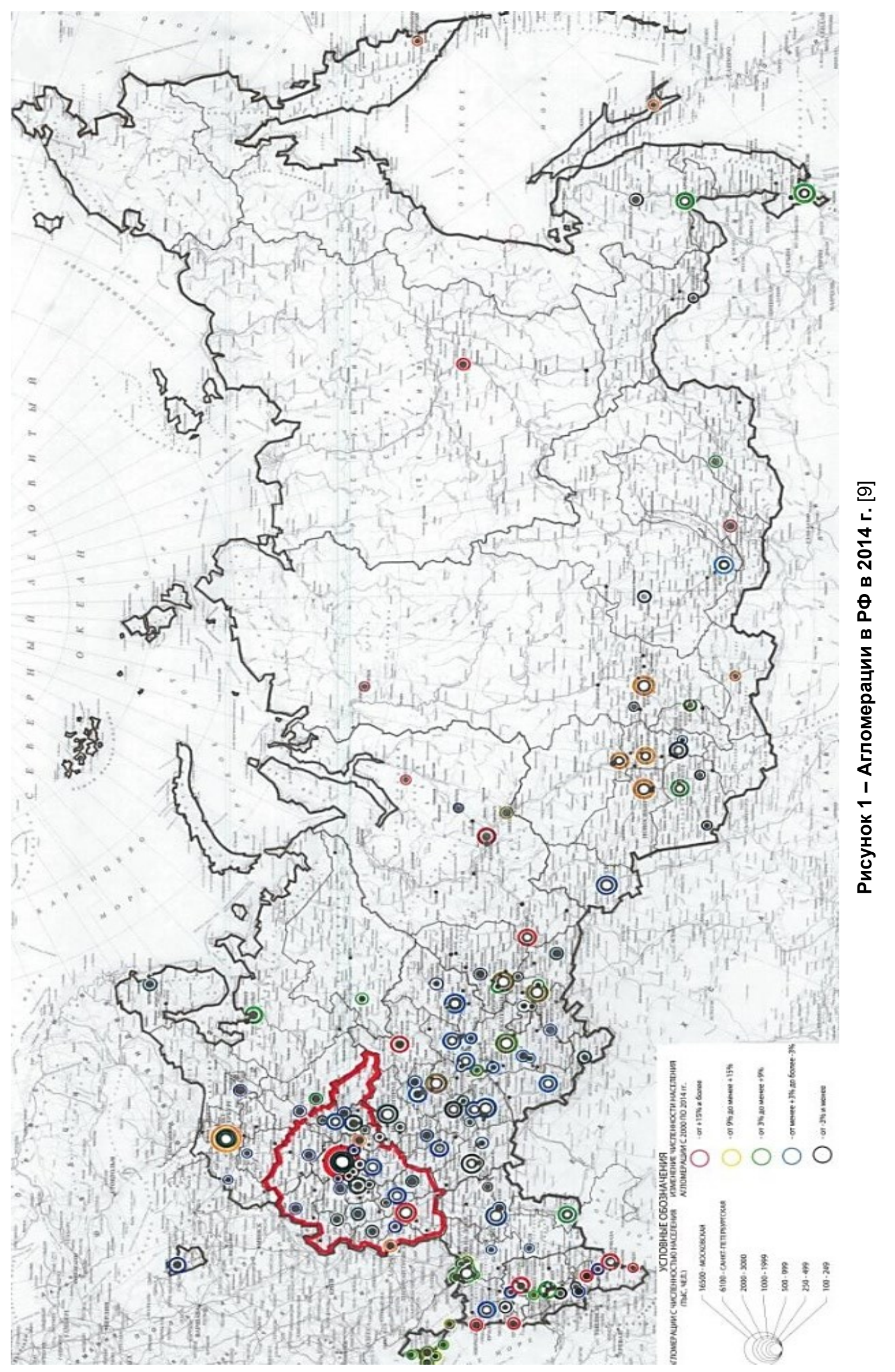


Таблица 2 - Систематизация расположенных на территории России агломераций

\begin{tabular}{|l|c|c|}
\hline $\begin{array}{c}\text { Численность населения } \\
\text { в агломерации, тыс. чел. }\end{array}$ & $\begin{array}{c}\text { Количество агломераций } \\
\text { на территории РФ }\end{array}$ & $\begin{array}{c}\text { Суммарное число жителей } \\
\text { в агломерациях, млн чел. }\end{array}$ \\
\hline Более 1000 & 17 & Более 44 \\
\hline От 500 до 100 & 28 & Более 19 \\
\hline От 250 до 500 & 45 & Более 15 \\
\hline От 100 до 250 & 34 & Более 5 \\
\hline
\end{tabular}

Сохранение выявленных тенденций пространственного развития России в долгосрочной перспективе представляет угрозу территориальной целостности и национальной безопасности. В целях преодоления данных негативных перспектив, рассматриваемых в рамках инерционного сценария пространственного развития, в федеральном законе № 172-Ф3 от 28.06.2014 г. «О стратегическом планировании в РФ» закреплена разработка Стратегии пространственного развития РФ.

Модели пространственного развития Российской Федерации. В ходе исследования проанализированы перспективные модели реализации стратегии пространственного развития страны [10], в том числе:

1) полицентрическая модель, основанная на формировании и приоритетном развитии поляризованного каркаса системы расселения на базе крупнейших агломераций;

2) равномерно-иерархическая модель, основанная на создании равномерно распределенной по территории страны полосы расселения, структурированной на шесть иерархических уровней в зависимости от масштаба центра расселения;

3) кластерно-сетевая модель, базирующаяся на приоритетной трансформации существующих и потенциальных урбанизированных территорий в надагломерационную структуру расселения на основе сетевых кластеров.

Проведен сравнительный анализ обозначенных моделей, на основе которого получены следующие выводы. Полицентрическая модель пространственного развития преимущественно ориентирована на приоритетное усиление точечных и линейных элементов каркаса экономического пространства страны, формируемого системами расселения шестого (национального) иерархического уровня. К недостаткам данной модели относятся высокие риски депопуляции и социально-экономической деградации площадей, составляющих более 90 \% исторически заселенной и хозяйственно освоенной территории России [11].

Равномерно-иерархическая модель ориентирована на минимизацию территориальных диспропорций социально-экономического развития и качества жизни населения, преодоление разрывов экономического пространства страны. К недостаткам относятся необходимость масштабных капиталовложений и риски смещения приоритетов инвестиционной и инфраструктурной политики в сторону развития неурбанизированных территорий, что может существенно снизить темпы прогрессирования высокотехнологичного промышленного производства, традиционно тяготеющего к урбанизированным агломерациям [12].

Кластерно-сетевая модель, по нашему мнению, является наиболее соответствующей стоящим перед Россией глобальным вызовам, представляя собой проект новой территориальной структуры страны, способной сохранить единство экономического и культурного пространства. Преимуществом такой модели выступает формирование взаимосвязанной сети инновационных кластеров (мультикластеров), интегрирующих на межрегиональном уровне промышленное производство как в традиционных секторах экономики, так и в высокотехнологичных. Организация сети инновационных кластеров приведет к стимулированию внутреннего спроса на инновации и развитию человеческого капитала, что в свою очередь окажет благоприятное внешнее воздействие на экономику регионов в целом и создаст предпосылки развития неурбанизированных территорий. К ограничениям реализации кластерно-сетевой модели относятся требования вложения значительных объемов инвестиций в инфраструктуру сети кластеров, увеличения эффективности внедрения инноваций в реальный сектор экономики, повышения степени институционального развития и качества управленческих решений на региональном уровне [13].

Далее рассмотрены предполагаемые эффеекты реализации кластерно-сетевой модели. Предлагаемая стратегия пространственного развития России на основе сети кластеров направлена на решение следующих задач в рамках оптимизации структуры экономического пространства страны:

- преодоление инерции и негативных тенденций существующей структуры агломерации населения и производительных сил на основе реализации «надагломерационных» социальноэкономических эфффектов, достигаемых за счет комплексной пространственной интеграции территорий соседних агломераций в рамках сети кластеров;

- формирование в европейской и азиатской частях России 15 центров межрегиональной интеграции и кластеризации высокотехнологичного производства с экономическим потенциалом, сопоставимым с отдельными государствами и макрорегионами Европейского союза;

- минимизация разрывов экономического пространства страны, снижение уровня дифференциации социально-экономического развития урбанизированных и неурбанизированных территорий.

Прогноз пространственного развития страны на основе кластерно-сетевой модели представлен на рисунке 2 . 

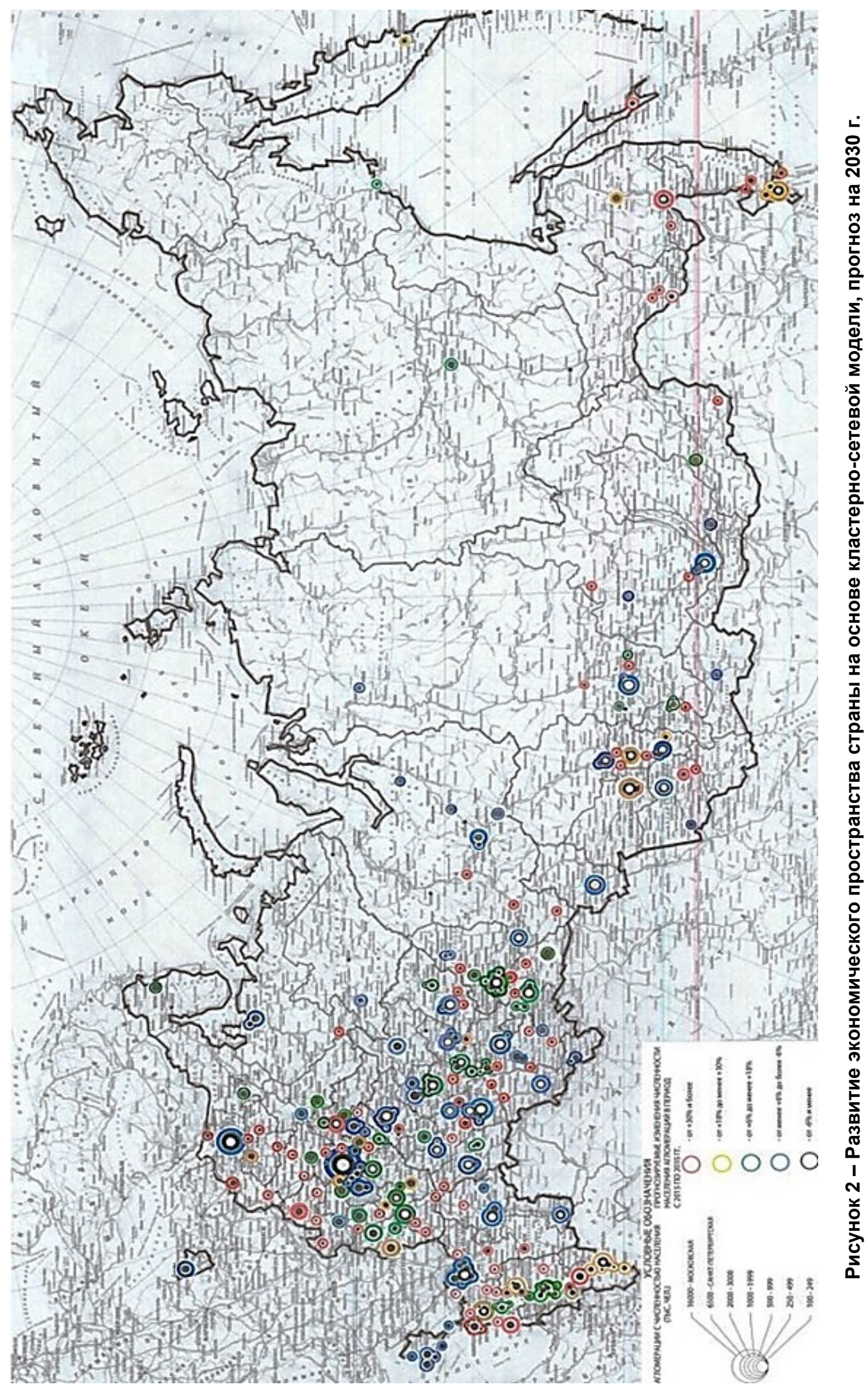
Выводы. Реализация рассмотренной кластерно-сетевой модели пространственного развития России в потенциале может иметь следующие социально-экономические эффректы. Совокупная площадь сети кластеров составит более 2 млн км², что соответствует примерно 12-15 \% общей площади территории страны и 30-35 \% основной полосы расселения. В качестве базового положительного эфффекта ожидается качественная трансформация структуры агломераций, а именно:

- в рамках сети кластеров площадь урбанизированной территории агломераций составит до 1 млн км², при этом площадь неурбанизированных зон, получающих внешние эффекты кластерного развития, возрастет до 1,5 млн км²;

- общая численность населения в рамках сети кластеров составит до 100 млн чел., при этом на долю проживающих в агломерациях в рамках сети кластеров будет приходиться до 75 млн;

- в результате формирования в рамках сети кластеров новых агломераций (преимущественно с численностью населения до 250 тыс. чел.) количество агломераций с численностью до 1 млн увеличится более чем в 1,5 раза (общая численность населения в них достигнет 65 млн чел.);

- ожидается стабилизация Московской агломерации (Московского столичного региона) на уровне 18 млн жителей;

- общая численность населения в агломерациях с количеством жителей более 1 млн составит около 30 млн чел.;

- общее число проживающих на неурбанизированных территориях Российской Федерации будет равняться приблизительно 50 млн чел. в основном за счет локализации таких территорий в рамках сети кластеров, где численность населения неурбанизированных зон составит до 25 млн чел.

Таким образом, на базе анализа стратегических альтернатив пространственного развития РФ сделан вывод об оптимальности реализации кластерно-сетевой модели трансформации экономического пространства. В данном случае пространственную основу развития территории России формирует сеть кластеров, интегрирующая соседние урбанизированные территории или группы менее компактно расположенных агломераций. Рассматриваемые кластеры интегрируют производство, а также объекты инженерной, транспортной и социальной инфраструктуры двух и более соседних субъектов РФ. При этом каждый кластер рассматривается как потенциальная основа создания макрорегиона.

Кластерно-сетевая модель предполагает активизацию горизонтальных коммуникаций, развитие инфраструктуры и институциональной среды в целях интеграции рынков капитала, инвестиций и труда, оптимизации товарных и информационных потоков, повышения эффективности бюджетных, налоговых и тарифных механизмов регулирования экономики. Сетевая структура кластеров формирует новый тип пространственного каркаса расселения страны, при этом подразумевается, что не вошедшие в состав кластеров территории получат предпосылки к социально-экономическому развитию за счет организации устойчивых транспортно-коммуникационных связей между кластерами.

\section{Ссылки и примечания:}

1. Работа выполнена в рамках гранта президента Российской Федерации для государственной поддержки молодых российских ученых № МК-1479.2017.6.

2. О стратегическом планировании в РФ [Электронный ресурс] : федер. закон № 172-ФЗ от 28 июня 2014 г. Доступ из справ.-правовой системы «КонсультантПлюс».

3. Волчкова И.В., Минаев Н.Н. Теория и практика управления развитием агломераций : монография. Томск, 2014. 234 c. ; Demographia World Urban Areas (Built-Up Urban Areas or Urban Agglomerations) [Электронный ресурс]. 14 ${ }^{\text {th }}$ annual ed. 2018. April. URL: http://www.demographia.com/db-worldua.pdf (дата обращения: 01.10.2018).

4. Козлова О.А., Макарова М.Н. Научно-методические вопросы мониторинга пространственной локализации социально-трудовых систем. Екатеринбург, 2014. 128 с. ; Перцик Е.Н. Крупные городские агломерации: развитие, проблемы проектирования // Проблемы развития агломераций России. М., 2009. С. 34-46.

5. Таблицы в статье разработаны Д.Л. Напольских.

6. Гранберг А.Г. Пространственный аспект социально-экономического развития // К Программе социально-экономического развития России 2008-2016 : научный доклад. М., 2008. С. 166-172.

7. Концепция Стратегии пространственного развития Российской Федерации на период до 2030 г. ГЭлектронный ресурс] : проект // Министерство экономического развития Российской Федерации. URL: http://economy.gov.ru/minec/documents/VostrebDocs (дата обращения: 01.10.2018).

8. Агломерационный фактор в контексте территориального развития регионов Дальнего Востока / О.А. Козлова, А.Г. Шеломенцев, Т.В. Терентьева, М.Н. Макарова // Международный журнал прикладных и фундаментальных исследований. 2014. № 10. С. 89-93.

9. Рисунки в статье взяты из следующего источника: Концепция ...

10. Волчкова И.В., Минаев Н.Н. Модели управления агломерациями: международный опыт и российская практика // Экономика и управление. 2013. № 11 (108). С. 53-57 ; Концепция ... ; Нещадин А.А., Прилепин А.М. Городские агломерации как инструмент динамичного социально-экономического развития регионов России [Электронный ресурс] // Информационный сайт экспертных групп по работе над Стратегией-2020. 2011. URL: http://2020strategy.ru/g12/documents/32581727.html (дата обращения: 01.10.2018). 
11. Атаева А.Г., Уляева А.Г. Исследование фракторов формирования и развития городских агломераций как направления усиления межтерриториального взаимодействия в регионе // Экономика и предпринимательство. 2015. № 12-1 (65-1). C. 369-373.

12. Перцик Е.Н. Указ. соч.

13. Артоболевский С.С. Меняю одну агломерацию на два кластера в разных экономических районах // Российское экспертное обозрение. 2007. № 4-5 (22). С. 11-13.

\section{References:}

Artobolevsky, SS 2007, 'One Agglomeration Should Be Changed into Two Clusters in Different Economic Regions', Rossiyskoye ekspertnoye obozreniye, no. 4-5 (22), pp. 11-13, (in Russian).

Ataeva, AG \& Ulyaeva, AG 2015, 'A Study of the Development Factors in Urban Agglomeration as a Trend towards Enhancing the Inter-Territorial Cooperation in the Region', Ekonomika i predprinimatel'stvo, no. 12-1 (65-1), pp. 369-373, (in Russian).

Demographia World Urban Areas (Built-Up Urban Areas or Urban Agglomerations) 2018, 14th annual ed., April, viewed 01 October 2018, <http://www.demographia.com/db-worldua.pdf>.

Granberg, AG 2008, 'The Spatial Aspect of the Social and Economic Development', K Programme sotsial'no-ekonomicheskogo razvitiya Rossii 2008-2016: nauchnyy doklad, Moscow, pp. 166-172, (in Russian).

Kozlova, OA \& Makarova, MN 2014, The Scientific and Methodological Issues of Monitoring of the Spatial Localization of Social and Labor Systems, Yekaterinburg, 128 p., (in Russian).

Kozlova, OA, Shelomentsev, AG, Terentyeva, TV \& Makarova, MN 2014, 'The Agglomeration Factor in the Context of the Territorial Development of the Far Eastern Regions', Mezhdunarodnyy zhurnal prikladnykh i fundamental'nykh issledovaniy, no. 10, pp. 89-93, (in Russian).

Neshchadin, AA \& Prilepin, AM 2011, 'Urban Agglomeration as a Tool for the Dynamic Social and Economic Development of Russian Regions', Informatsionnyy sayt ekspertnykh grupp po rabote nad Strategiyey-2020, viewed 01 October 2018, <http://2020strategy.ru/g12/documents/32581727.html>, (in Russian).

Pertsik, EN 2009, 'Large Urban Agglomeration: Development, Design Problems', Problemy razvitiya aglomeratsiy Rossii, Moscow, pp. 34-46, (in Russian).

Volchkova, IV \& Minaev, NN 2013, 'Agglomeration Management Models: International and Russian Practice', Ekonomika i upravleniye, no. 11 (108), pp. 53-57, (in Russian).

Volchkova, IV \& Minaev, NN 2014, Theoretical and Practical Management of Agglomeration Development, monograph, Tomsk, 234 p., (in Russian). 